\title{
Histopathological changes in the Brain Tissue of Africa Catfish exposure to Glyphosate Herbicide.
}

\author{
${ }^{1 *}$ ERHUNMWUNSE, NO; ${ }^{2}$ EKAYE SA; ${ }^{3}$ AINERUA, MO; ${ }^{4}$ EWERE, EE \\ ${ }^{1,2,3,4}$ Department of Animal and Environmental Biology, \\ faculty of Life Sciences, \\ University of Benin, P.M.B 1154, Benin City. Nigeria \\ *Corresponding Author's Email: donsazy@yahoo.co.uk,nosakhare.erhunmwunse@uniben.edu
}

KEYWORD: Histopathology, glyphosate herbicide, Clarias gariepinus

\begin{abstract}
One hundred and twenty normal post juvenile catfish (Clarias gariepinus) of both sexes with a mean weight of $135.44 \pm 1.99 \mathrm{~g}$ and mean length of $28.32 \pm 0.844 \mathrm{~cm}$ were purchased from Osayi farm. They were kept in 601 aquaria at $27.5 \pm 0.4{ }^{\circ} \mathrm{C}, \mathrm{pH} 7.3$, with 12:12 $\mathrm{h}$ photoperiod, well aerated, provided with external filtration and a layer of gravel on the bottom. Histopathological alteration in the brain tissues when the fish were exposed to various concentrations $(18 \mathrm{mg} / \mathrm{L}, 32 \mathrm{mg} / \mathrm{L}$ and $75 \mathrm{mg} / \mathrm{L})$ of glyphosate for a period of $7-28$ days revealed that glyphosate hervicide may be neurotozic to post juvenile African catfish $C$. gariepinus as characterized by severe degeneration of dark-stained purkinje neurons, oedema, vacuolar changes with empty spaces which appeared as moth eaten area and showed proliferation of glial cells. There is need for more research work on the histopathology of brain tissue of fish exposed to pesticide. @ JASEM
\end{abstract}

\section{http://dx.doi.org/10.4314/jasem.v18 i2.19}

Introduction:Nervous and sensory systems are an integral part of these adaptations and the relative contributions of phylogeny and ecology in determining brain and sense organ morphology have been a longstanding question in ecomorphology. Although the relationships between brain morphology and ecology are well established for some teleost fishes (Evans, 1931; Evans, 1952; Schnitzlein, 1964; Davis and Miller, 1967; Ito et al., 2007), the strength of this relationship has subsequently been found to vary in different taxa. For example within North American catostomids (Miller and Evans, 1965), African Great Lakes cichlids (Huber et al., 1997), and deep-sea eels and grenadiers (Wagner, 2002), the interspecific variation in sensory and association areas of brains is tightly correlated with ecology, especially habitat and feeding. However in some European cyprinids (Kotrschal and Palzenberger, 1992) and coral reef dwelling perciform angelfish and butterflyfishes (Bauchot et al., 1989), interspecific variation is not as pronounced and the link between brain morphology and ecology is less robust. In a comprehensive review of this field, Kotrschal et al., (1998) noted that primary sensory areas of the brain relate more closely to feeding whereas integration centers reflect differences in microhabitat, and in phyletically advanced teleosts like perciforms there is a relative shift of brain mass from sensory areas to integration centers. As a means of apportioning the influence of phylogenetic and ecological factors shaping brain morphology, Kotrschal et al., (1998) called for investigations of closely related perciform species that differ in body size, habitat utilization and behaviour.
This study was therefore carried out to determine the histopathological alterations in the brain of $C$. gariepinus when exposed to glyphosate pesticides under laboratory condition

\section{MATERIALS AND METHOD}

Experimental fish specimen and chemicals: One hundred and twenty normal post juvenile Clarias gariepinus of both sexes with a mean weight of $135.44 \pm 1.99 \mathrm{~g}$ and mean length of $28.32 \pm 0.844 \mathrm{~cm}$ were purchased from Osayi farms in Benin City, Edo state. They were kept in 601 aquaria at $27.5 \pm 0.4{ }^{\circ} \mathrm{C}$, $\mathrm{pH} 7.3$, with 12:12 h photoperiod. They were left unfed in the first 2 days to adapt to a change in environment before feeding them with the fish diet. Laboratory aquaria were well aerated and provided with external filtration and a layer of gravel on the bottom. Fish were normally fed once a day with pelleted commercial food (Durante Aquaculture fish concentration-2mm). They were allowed to acclimate to captivity conditions for two month prior to taking the blood samples. Careful netting and handling was implemented to minimize stress. The commercial formulation of glyphosate (360 g/l-41 w.wt IPA) at five nominal concentrations 72, 54, 32 and $18 \mathrm{mg} / \mathrm{L}$ were used. These concentrations were defined taking into account: the result of the range finding test.

Histological Procedure: The brains were removed and washed in saline water to remove blood and fixed in aqueous Bouins's fixative for 24 hours. They were then dehydrated through graded series of ethanol and embedded in parafifin wax (M.P. 58-68 ${ }^{\circ} \mathrm{c}$ ). Blocks 
were prepared and sectioned at a thickness of 67 microns using Microtome. The sections were deparaffinized in xylene and stained with haematoxylin-eosin (HE). Changes induced by glyphosate exposure in the gills were analyzed and photographed under photomicroscope along with control group.

\section{RESULTS AND DISCUSSION}

The histological alterations in the brain of $C$. gariepinus exposed to $72 \mathrm{mg} / \mathrm{L}$ glyphosate after 7 days showed dark-stained degenerating neurons and vacuolar changes with empty spaces which appeared as moth eaten area ( $\mathrm{G}$ and $\mathrm{H}$ ) (Plate $6 \mathrm{~b}$ ). After the $14^{\text {th }}$ day of exposure to same concentration of glyphosate, fish brain showed dark-stained degenerating neurons and vacuolar changes with empty spaces which appeared as moth eaten area (Plate 6f). Vacuolar changes with empty spaces which appeared as moth eaten area (Plate 6j) characterized the fish brain exposed to $72 \mathrm{mg} / \mathrm{L}$ after the $21^{\text {st }}$ day of exposure. After the $28^{\text {th }}$ day of exposure to same concentration, fish brain showed vacuolar changes with empty spaces which appeared as moth eaten area $(G)$ (Plate $6 n)$.

Fish brain exposed to $54 \mathrm{mg} / \mathrm{L}$ glyphosate after the $7^{\text {th }}$ day showed dark-stained degenerating neurons $(\mathrm{K})$ (Plate 6c). After the $14^{\text {th }}$ and $21^{\text {st }}$ day of exposure to $54 \mathrm{mg} / \mathrm{L}$ glyphosate, fish brain showed dark-stained degenerating neurons $(\mathrm{K})$ and vacuolar changes with empty spaces which appeared as moth eaten area $(\mathrm{N})$ (Plate $6 \mathrm{~g}$ and $6 \mathrm{k}$ ). After the $28^{\text {th }}$ day of exposure to same concentration of glyphosate, fish brain showed dark-stained degenerating neurons (K) (Plate 6o).

After the $7^{\text {th }}$ day of exposure to $32 \mathrm{mg} / \mathrm{L}$ glyphosate fish brain showed dark-stained degenerating neurons (J) (Plate 6d). Vacuolar changes with empty spaces which appeared as moth eaten area characterized the fish brain exposed to $32 \mathrm{mg} / \mathrm{L}$ after 14 and 21 days of exposure. After the $28^{\text {th }}$ day of exposure to same concentration, fish brain showed dark-stained degenerating neurons (Y) and vacuolar changes with empty spaces which appeared as moth eaten area $(\mathrm{Z})$ (Plate 6p)

After the $7^{\text {th }}$ day of exposure to the lowest concentration, fish brain showed proliferation of glial cells (F and L) (Plate 6e). Fish brain exposed to 18 $\mathrm{mg} / \mathrm{L}$ after the $14^{\text {th }}$ day showed vacuolar changes with empty spaces (S) (Plate 6i). After the $21^{\text {st }}$ day of exposure to same concentration, fish brain showed vacuolar changes with empty spaces which appeared as moth eaten area (Plate $6 \mathrm{~m}$ ). Fish brain showed dark-stained degenerating neurons and vacuolar changes with empty spaces which appeared as moth eaten area (Plate 6q) after 28 days of exposure to the lowest concentration of glyphosate.

Histopathological report in literature is scarce for fish brain pathology. Pathological examination of nervous system is an important component of neurotoxicology, but features of the brain and spinal cord can make this assessment challenging (Jortner, 2005). He further stated the need for careful histopathological evaluation of neuronal lesions evolving following exposure to convulsion-induced dosages of these pesticides especially organophosphorus nerve agents elicit a sequence of events leading to acute neuronal necrosis.

Histopathological alteration in the brain of $C$. gariepinus exposed to varying concentration of glyphosate herbicide in this present study revealed that the herbicide may be neurotoxic to post juvenile African catfish $C$. gariepinus as characterized by severe degeneration of dark-stained Purkinje neurons, oedema, vacuolar changes with empty spaces which appeared as moth eaten area and showed proliferation of glial cells. This report agrees with the findings of Sarma et al., (2009) who examined brain histology of the spotted murrel, Channa punctatus after 96 hours exposure to endosulfan. Exposed fish brain showed mild necrosis and vacuolar changes. Again similar alterations were observed in the brain of toad Buffo regularis exposed to endosulfan and diazinon (Tongo, 2010).

Brain Pathology: Histopathological alterations were evident in the brain of $C$. gariepinus exposed to sublethal concentrations of Glyphosate herbicide for 28 days (Plate 1). Histological study of brain showed no obvious histological changes in the control. The brain showed many intensely stained dark neurons present in the cerebral cortex, shrunken dark blue stained (basophilic) cell bodies and proximal dendrites in the cells. 


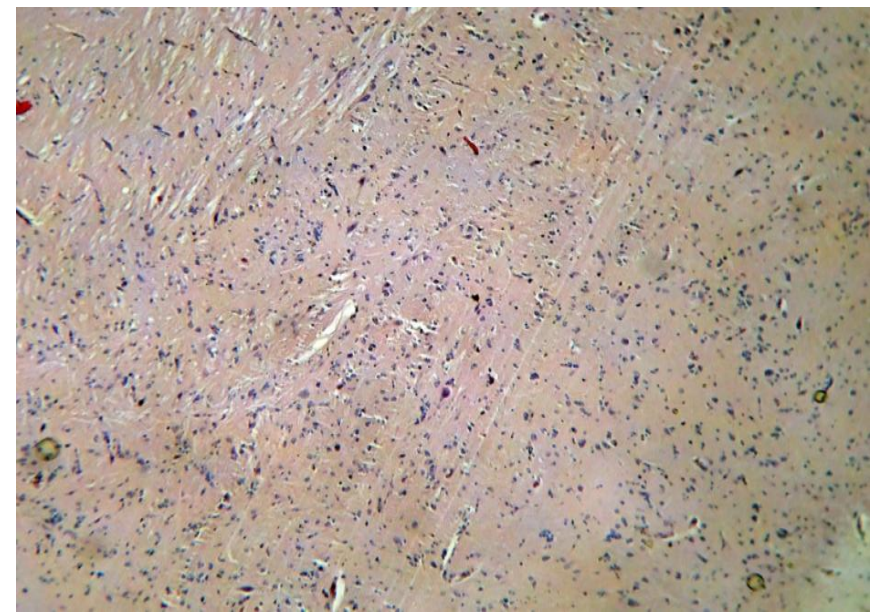

Plate 1a: Microphotograph of Controlled Catfish brain showing intensely stained dark neuron present in the cerebral cortex and shrunken dark blue stained (basophilic) cell bodies (H \& E stain x100).

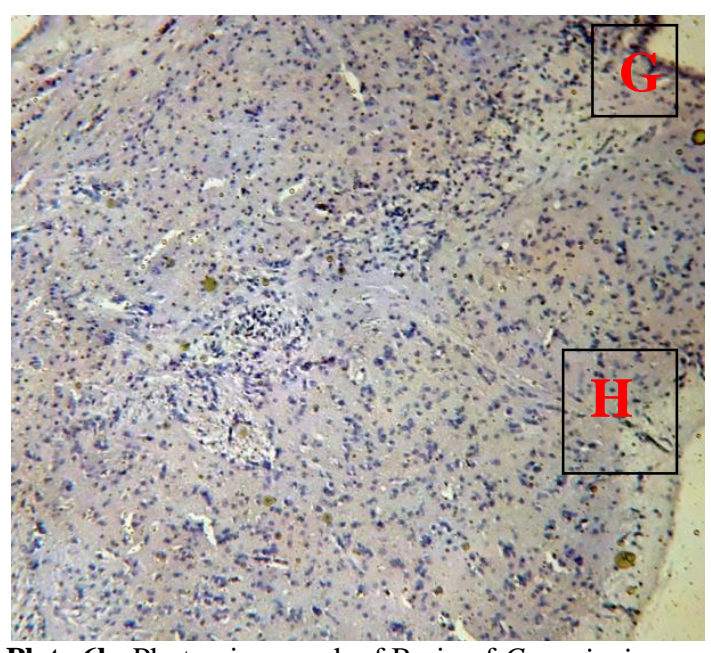

Plate 6b: Photomicrograph of Brain of $C$. gariepinus exposed to $72 \mathrm{mg} / \mathrm{L}$ glyphosate. Dark-stained degenerating neurons and vacuolar changes with empty spaces which appeared as moth eaten area $(\mathrm{G}$ and $\mathrm{H})(\mathrm{H}$ $\&$ E Stain x100).

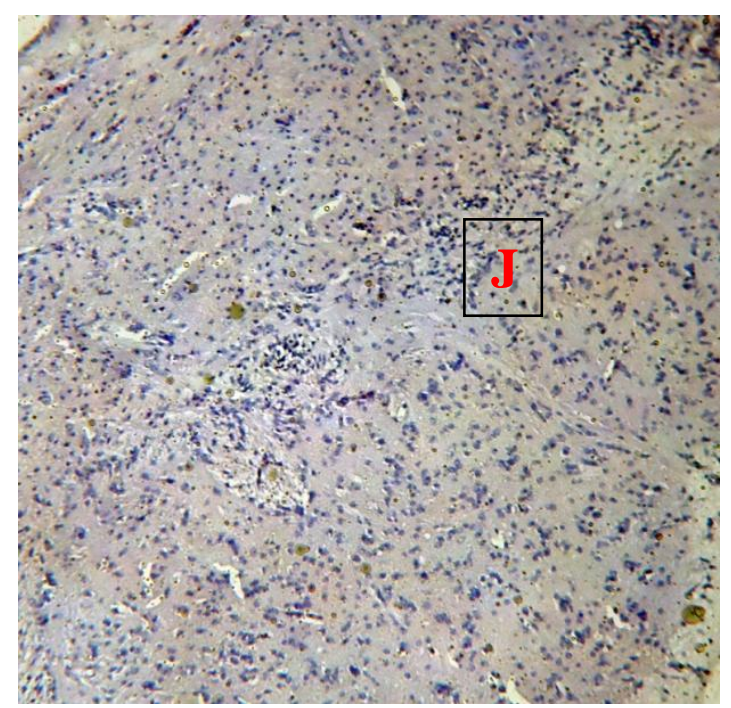

Plate 6d: Photomicrograph of Brain of C. gariepinus exposed to $32 \mathrm{mg} / \mathrm{L}$ glyphosate. Dark-stained degenerating neurons (J) (H \& E Stain x100).

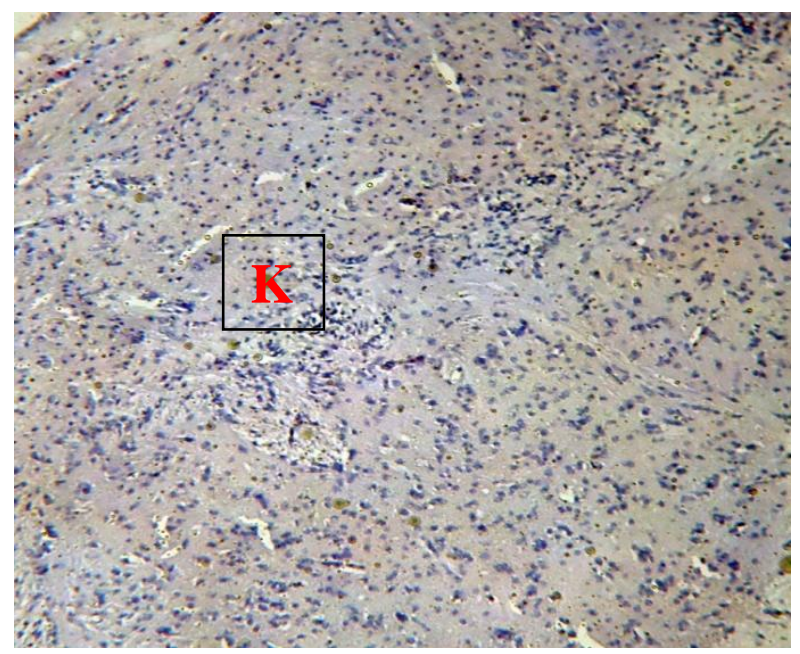

Plate 6c: Photomicrograph of Brain of C. gariepinus exposed to $54 \mathrm{mg} / \mathrm{L}$ glyphosate. Dark-stained degenerating neurons (K) (H \& E Stain x100).

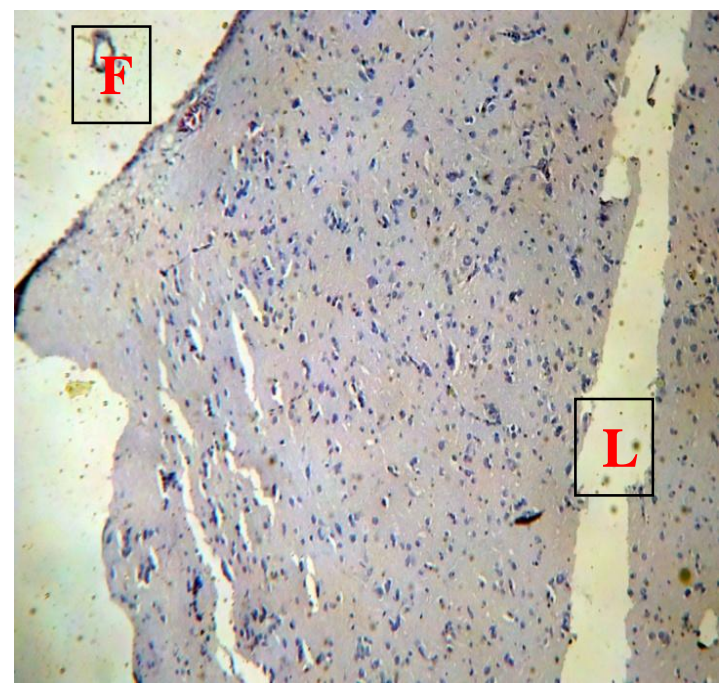

Plate 6e: Photomicrograph of Brain of C. gariepinus exposed to $18 \mathrm{mg} / \mathrm{L}$ glyphosate. Proliferation of glial cells (F and L) (H \& E Stain x100). 
Plate 6b-e: Histopathological changes observed after the 7day of exposure.

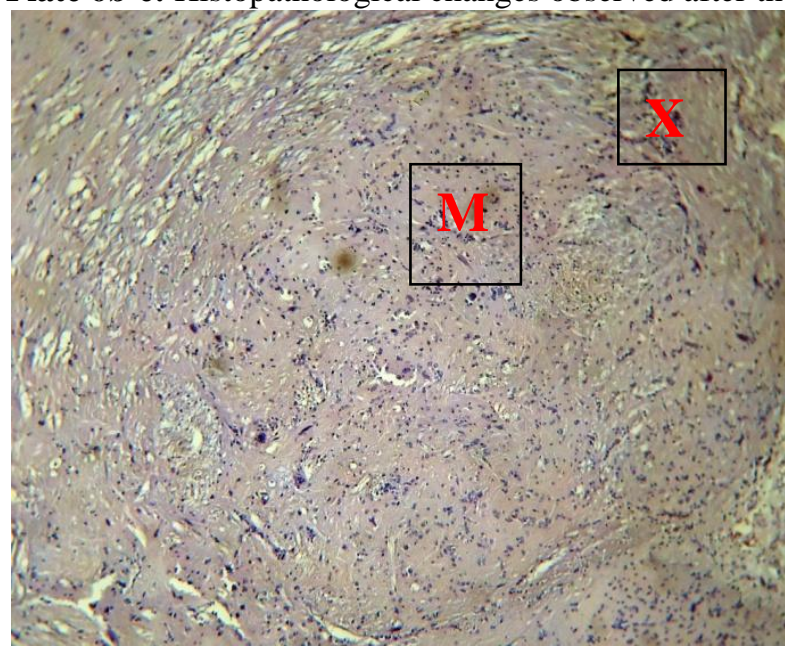

Plate 6f: Photomicrograph of Brain of $C$. gariepinus exposed to $72 \mathrm{mg} / \mathrm{L}$ glyphosate. Dark-stained degenerating neurons and vacuolar changes with empty spaces which appeared as moth eaten area $(\mathrm{H} \&$ E Stain x100).

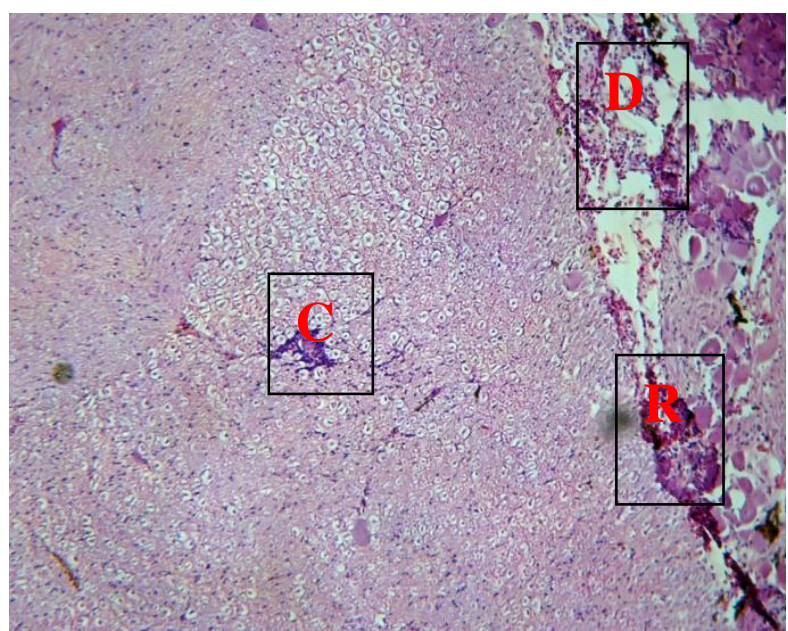

Plate 6h: Photomicrograph of Brain of C. gariepinus exposed to $32 \mathrm{mg} / \mathrm{L}$ glyphosate. Vacuolar changes with empty spaces which appeared as moth eaten area (H \& E Stain $\mathrm{x} 100)$.

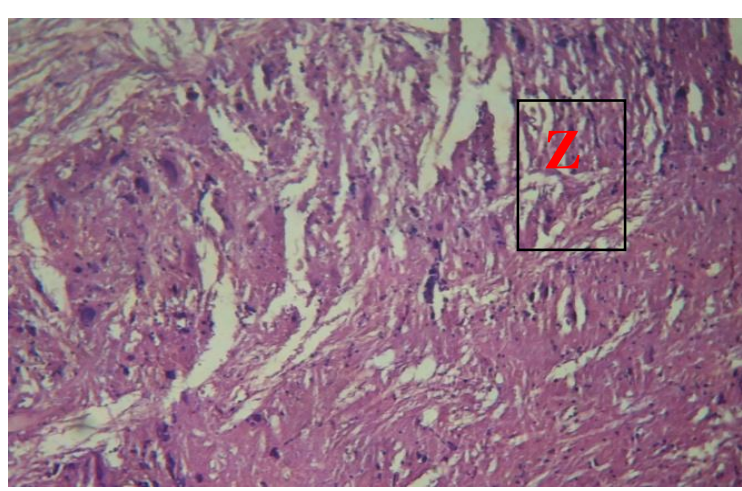

Plate 6j: Photomicrograph of Brain of C. gariepinus exposed to $72 \mathrm{mg} / \mathrm{L}$ glyphosate. Vacuolar changes with empty spaces which appeared as moth eaten area (H \& E Stain x100).

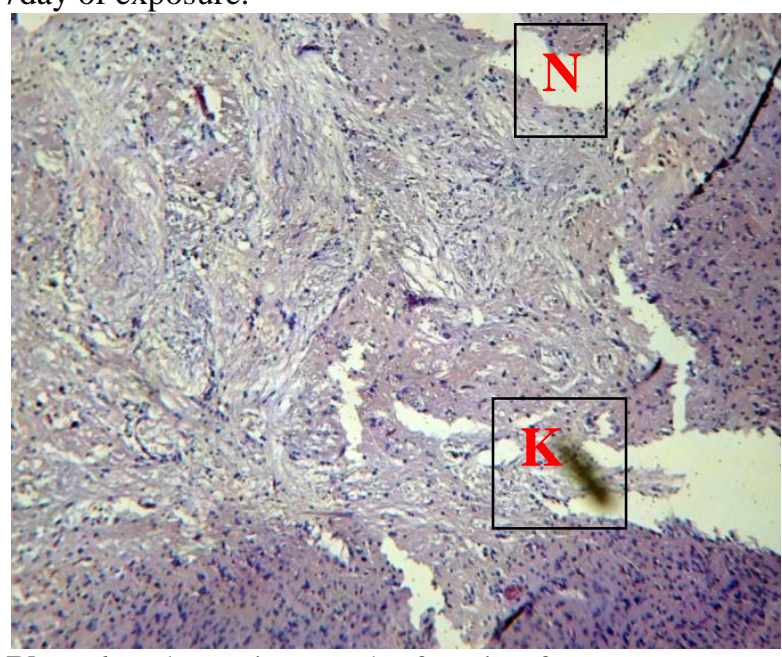

Plate 6g: Photomicrograph of Brain of $C$. gariepinus exposed to $54 \mathrm{mg} / \mathrm{L}$ glyphosate. Dark-stained degenerating neurons $(\mathrm{K})$ and vacuolar changes with empty spaces which appeared as moth eaten area $(\mathrm{N})$ (H \& E Stain x100).

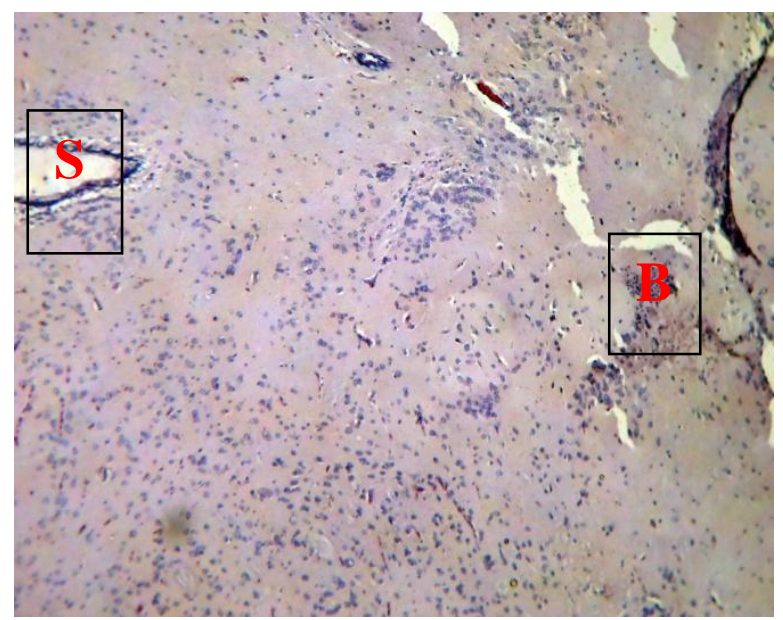

Plate 6i: Photomicrograph of Brain of C. gariepinus exposed to $18 \mathrm{mg} / \mathrm{L}$ glyphosate. Vacuolar changes with empty spaces (S) (H \& E Stain x100).

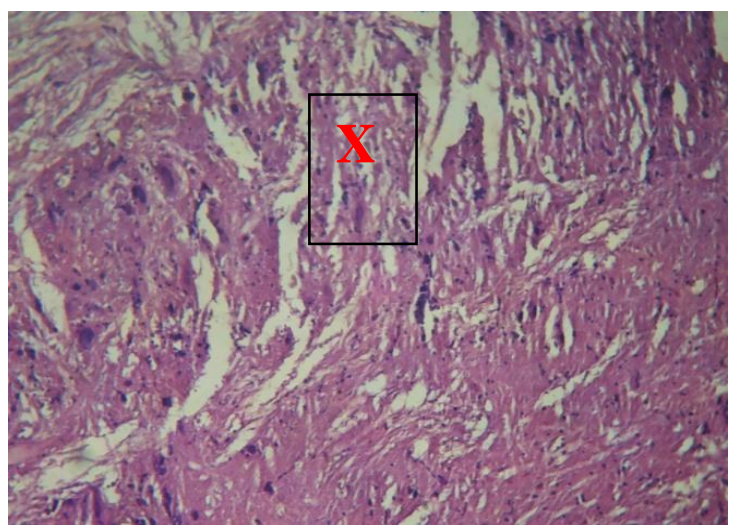

Plate 6k: Photomicrograph of Brain of C. gariepinus exposed to $54 \mathrm{mg} / \mathrm{L}$ glyphosate. Vacuolar changes with empty spaces which appeared as moth eaten area (H \& E Stain $\mathrm{x} 100)$. 


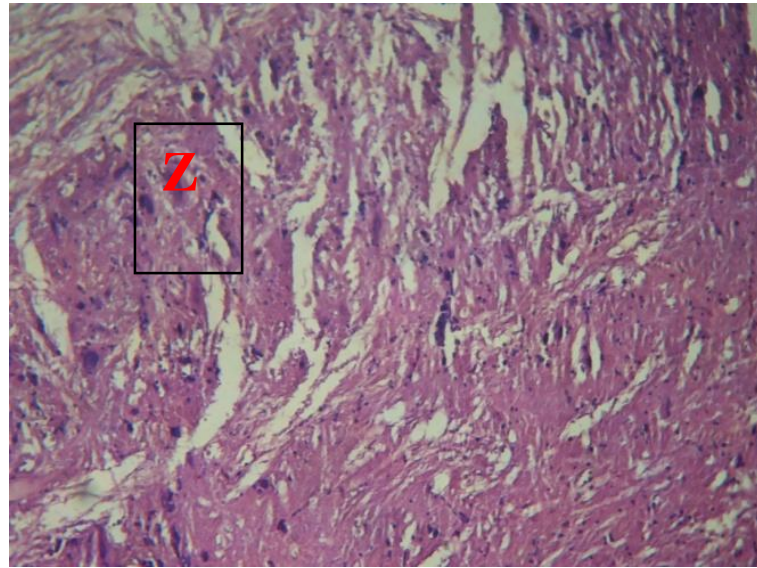

Plate 61: Photomicrograph of Brain of C. gariepinus exposed to $32 \mathrm{mg} / \mathrm{L}$ glyphosate. Vacuolar changes with empty spaces which appeared as moth eaten area (H \& E Stain $x 100$

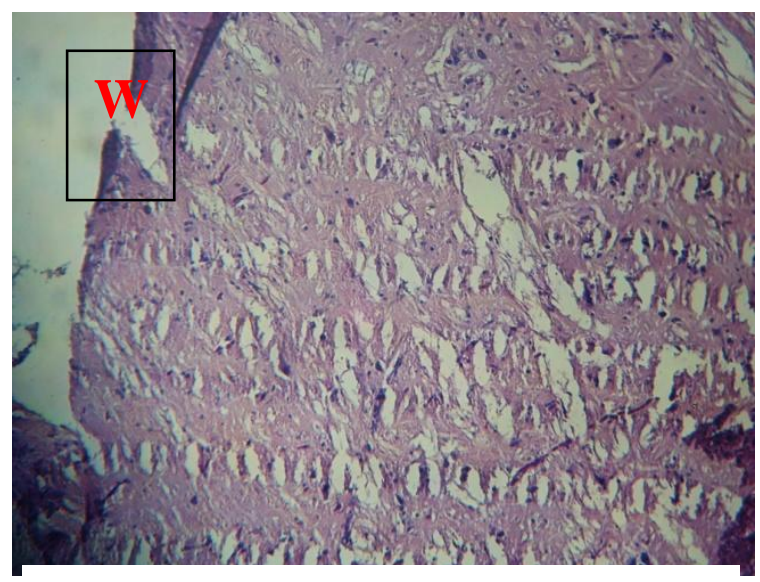

Plate 6m: Photomicrograph of Brain of C. gariepinus exposed to $18 \mathrm{mg} / \mathrm{L}$ glyphosate. Vacuolar changes with empty spaces which appeared as moth eaten area (H \& E Stain x100

Plate 6j-m: Histopathological changes observed after 21 days of exposure.

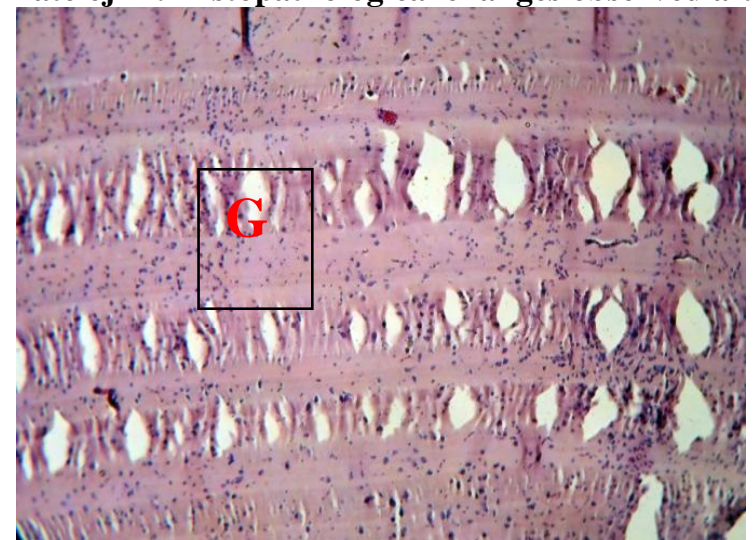

Plate 6n: Photomicrograph of Brain of C. gariepinus exposed to $72 \mathrm{mg} / \mathrm{L}$ glyphosate. Vacuolar changes with empty spaces which appeared as moth eaten area (G) (H \& E Stain x100).

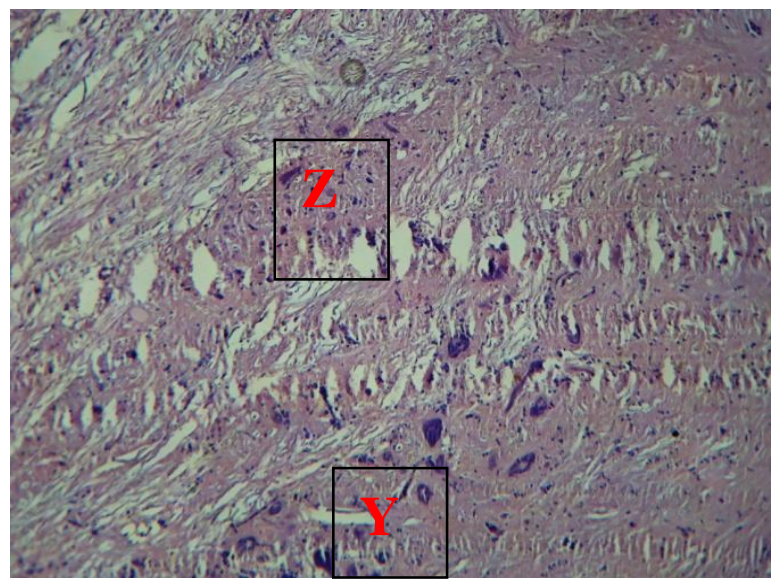

Plate 6p: Photomicrograph of Brain of C. gariepinus exposed to $32 \mathrm{mg} / \mathrm{L}$ glyphosate. Dark-stained degenerating neurons (Y) and vacuolar changes with empty spaces which appeared as moth eaten area $(\mathrm{Z})(\mathrm{H} \& \mathrm{E}$ Stain $\mathrm{x} 100)$.

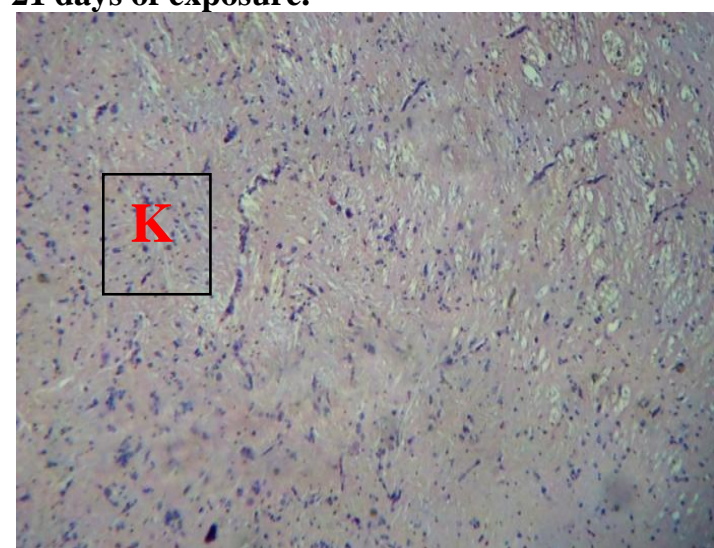

Plate 6o: Photomicrograph of Brain of C. gariepinus exposed to $54 \mathrm{mg} / \mathrm{L}$ glyphosate. Dark-stained degenerating neurons (K) (H \& E Stain x100).

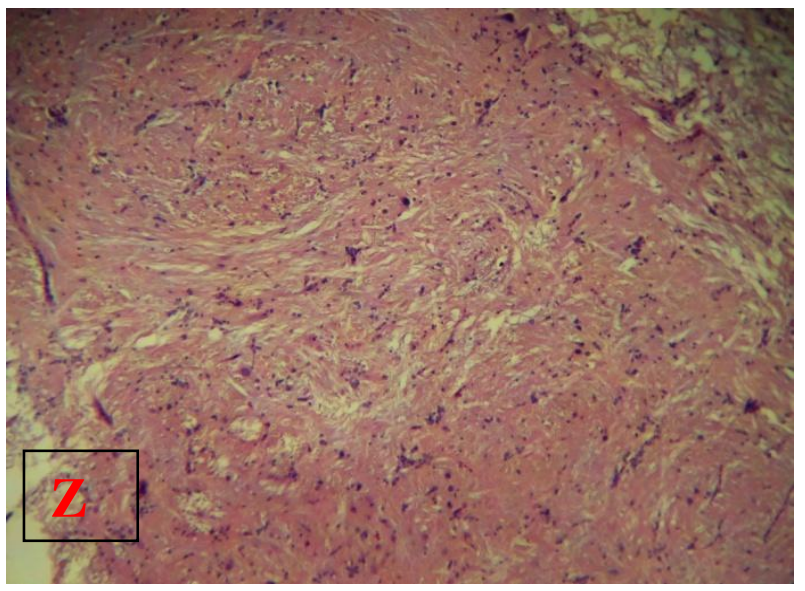

Plate 6q: Photomicrograph of Brain of C. gariepinus exposed to 18 $\mathrm{mg} / \mathrm{L}$ glyphosate. Dark-stained degenerating neurons and vacuolar changes with empty spaces which appeared as moth eaten area $(\mathrm{H} \&$ E Stain $\mathrm{x} 100)$.

Plate 6n-q: Histopathological changes observed after 28 days of exnosure 
Conclusion: In conclusion, the use of glyphosate herbicide should be carefully monitored since various concentrations of it can alter the brain tissue of post juvenile African catfish (C. gariepinus) as observed in the laboratory condition in this study. Also, more work should be done on the histopathology of the brain tissues of fish exposed to pesticide both in the laboratory and in the natural environment.

\section{REFERENCES}

Bauchot, R., Ridet, J. M. and Bauchot, M. L. (1989). The brain organization of butterflyfishes. Env. Biol. Fish 25:205-219.

Davis, B. J. and Miller, R. J. (1967). Brain patterns in minnows of the genus Hybopsis in relation to feeding habits and habitat. Copeia 1967:1-39.

Evans, H. E. (1952). The correlation of brain pattern and feeding habits in four species of cyprinid fishes. J. Comp. Neurol. 97:133-142.

Evans, H. M. (1931). A comparative study of the brains of British cyprinoids in relation to their habits of feeding, with special reference to the anatomy of the medulla oblongata. Proc. Roy. Soc. Lond. B. 108:233-257.

Huber, R., van Staaden, M. J., Kaufman, L. S. and Liem, K. F. (1997). Microhabitat use, trophic patterns, and the evolution of brain structure in African cichlids. Brain Behav. Evol. 50:167-182.

Ito, H., Ishikawa, Y., Yoshimoto, M. and Yamamoto, N. (2007). Diversity of brain morphology in teleosts: Brain and ecological niche. Brain Behav. Evol. 69:76-86.
Jortner, B. S. (2005). Neuropathological Assessment in Acute Neurotoxic States. The Dark Neuron. Journal of Medical Chemical, Biological and Radiological Defense 3:1-5.

Kotrschal, K. and Palzenberger, M. (1992). Neuroecology of cyprinids: Comparative, quantitative histology reveals diverse brain patterns. Env. Biol. Fish 33:135-152.

Kotrschal, K., van Staaden, M. J. and Huber, R. (1998). Fish brains: Evolution and environmental relationships. Rev. Fish Biol. Fisheries 8:373408 .

Miller, R. J and Evans H. E. (1965). External morphology of the brain and lips in catostomid fishes. Copeia 1965:467-487.

Sarma Dam, J., Kenyon, L. C., Hingley, S. T. and Shindler, K. S. (2009). Mechanisms of primary axonal damage in a viral model of multiple sclerosis. J. Neurosci. 29:10272-10280.

Schnitzlein, H. N. (1964). Correlation of habit and structure in the fish brain. Am. Zool. 4:2132

Tongo, I. I. (2010). Toxicological studies on the Effects of Agricultural pesticides (Endosulfan and Diazinon) on Adult Bufo regularis (Reuss, 1833). PhD Thesis, University of Benin. 271pp.

Wagner, H. J. (2002). Sensory brain areas in three families of deep-sea fish (slickheads, eels and grenadiers): comparison of mesopelagic and demersal species. Marine Biology 141:807-817. 